\title{
Age Effects on Serotonin Receptor 1B as Assessed by PET
}

\author{
David Matuskey ${ }^{1,2}$, Brian Pittman ${ }^{1}$, Beata Planeta-Wilson ${ }^{2}$, Espen Walderhaug ${ }^{1,3}$, Shannan Henry ${ }^{2}$, \\ Jean-Dominique Gallezot ${ }^{2}$, Nabeel Nabulsi ${ }^{2}$, Yu-Shin Ding ${ }^{2}$, Zubin Bhagwagar ${ }^{1,4}$, Robert Malison ${ }^{1}$, Richard E. Carson ${ }^{2}$, \\ and Alexander Neumeister ${ }^{5}$
}

\begin{abstract}
${ }^{1}$ Department of Psychiatry, Yale University School of Medicine, New Haven, Connecticut; ${ }^{2}$ Department of Diagnostic Radiology, Yale University School of Medicine, New Haven, Connecticut; ${ }^{3}$ Department of Addiction Treatment, Oslo University Hospital, Oslo, Norway; ${ }^{4}$ Bristol-Myers Squibb, Wallingford, Connecticut; and ${ }^{5}$ Department of Psychiatry, New York University School of Medicine, New York, New York
\end{abstract}

Previous imaging studies have suggested that there is an agerelated decline in brain serotonin (5-hydroxytryptamine) measures in healthy subjects. This paper addresses whether the availability of 5 -hydroxytryptamine receptor $1 \mathrm{~B}\left(5-\mathrm{HT}_{1 \mathrm{~B}}\right)$ is seen to decrease with aging via PET imaging. Methods: Forty-eight healthy control subjects (mean age $\pm S D, 30 \pm 10$ y; age range, 18-61 y; 33 men, 15 women) underwent ${ }^{11} \mathrm{C}-\mathrm{P} 943$ scanning on a high-resolution PET tomograph. Regions were examined with and without gray matter masking, the latter in an attempt to control for age-related gray matter atrophy on nondisplaceable binding potential $\left(\mathrm{BP}_{\mathrm{ND}}\right)$ as determined by a validated multilinear reference tissue model. Results: $5-\mathrm{HT}_{1 \mathrm{~B}} \mathrm{BP}_{\mathrm{ND}}$ decreased in the cortex at an average rate of $8 \%$ per decade without and $9 \%$ with gray matter masking. A negative association with age was also observed in all individual cortical regions. Differences in the putamen and pallidum (positive association) were significant after adjustment for multiple comparisons. No sex- or race-related effects on $5-\mathrm{HT}_{1 \mathrm{~B}} \mathrm{BP}_{\mathrm{ND}}$ were found in any regions. Conclusion: These findings indicate that age is a relevant factor for $5-\mathrm{HT}_{1 \mathrm{~B}}$ in the cortex of healthy adults.

Key Words: serotonin ${ }_{1 \mathrm{~B}} ; 5-\mathrm{HT}_{1 \mathrm{~B}} ; \mathrm{PET}$ imaging; $\left[{ }^{11} \mathrm{C}\right] \mathrm{P} 943$; aging

J Nucl Med 2012; 53:1411-1414

DOI: 10.2967/jnumed.112.103598

O the aging of the brain. Preclinical and clinical work has shown alterations in the functional and structural capacities of 5-hydroxytryptamine during aging $(1,2)$. In translational neuroimaging, decreases with age have been found for the serotonin transporter, the 5-hydroxytryptamine receptors $1 \mathrm{~A}$ and $2 \mathrm{~A}\left(5-\mathrm{HT}_{1 \mathrm{~A}}\right.$ and $5-\mathrm{HT}_{2 \mathrm{~A}}$, respectively), and for cerebral glucose metabolism after administration of a selective serotonin reuptake inhibitor in many cortical areas $(3-8)$.

\footnotetext{
Received Jan. 25, 2012; revision accepted May 9, 2012.

For correspondence or reprints contact: David Matuskey, Yale School of Medicine, 801 Howard Ave., New Haven, CT 06520.

E-mail: david.matuskey@yale.edu

Published online Jul. 31, 2012.

COPYRIGHT (C 2012 by the Society of Nuclear Medicine and Molecular Imaging, Inc.
}

Recently, evidence that aging has an effect on the 5-hydroxytryptamine system has also brought about a focus on $5-\mathrm{HT}_{1 \mathrm{~B}}(1,9) .5-\mathrm{HT}_{1 \mathrm{~B}}$ is part of the $5-\mathrm{HT}_{1}$ family and is a G-protein-coupled metabotropic receptor spanning 7 transmembranes (10). 5- $\mathrm{HT}_{1 \mathrm{~B}}$ is expressed as an autoreceptor on serotoninergic neurons, where it is the predominant presynaptic modulator of 5-hydroxytryptamine release in the brain, and as a heteroreceptor on nonserotoninergic neurons (10). Although the only clinically available $5-\mathrm{HT}_{1 \mathrm{~B}}$ medications are for headaches (the triptan class of $5-\mathrm{HT}_{1 \mathrm{~B} / \mathrm{D}}$ agonists), these receptors have become increasingly important in neurophysiologic functions and for behaviors as diverse as locomotor activity, drug abuse reinforcement (11), depression (12), and posttraumatic stress disorder (13), as well as learning, memory, and aggressive behavior (10).

Basic research in aging has shown large decreases (of $\leq 27 \%$ ) in the density of 5- $\mathrm{HT}_{1 \mathrm{~B}}\left(5-\mathrm{HT}_{1 \mathrm{~A}}\right.$ apparently did not decrease) in elderly rats $(9,14)$ and postsynaptic $5-\mathrm{HT}_{1 \mathrm{~B}}$ messenger RNA in several brain regions (14), raising the possibility that aged animals may have relatively specific reduced $5-\mathrm{HT}_{1 \mathrm{~B}}$ function. In addition, another study focused on $5-\mathrm{HT}_{1 \mathrm{~B}}$ and aging and demonstrated that $5-\mathrm{HT}_{1 \mathrm{~B}}$ knockout mice had an early age-related motor decline and decreased lifespan, thus increasing the plausibility that $5-\mathrm{HT}_{1 \mathrm{~B}}$ is an important component of normal aging (1). An interesting finding of that paper was a comparative phylogenetic conservation of a genetic age effect from mice to humans suggesting that $5-\mathrm{HT}_{1 \mathrm{~B}}$ may be a modulator of aging across species (1). To date, however, possible effects of aging on $5-\mathrm{HT}_{1 \mathrm{~B}}$ have not, to our knowledge, been studied in healthy humans. The aim of this study was to investigate age effects in the brain of healthy subjects via the highly selective $5-\mathrm{HT}_{1 \mathrm{~B}}$ ligand ${ }^{11} \mathrm{C}-\mathrm{P} 943$ using PET imaging.

\section{MATERIALS AND METHODS}

\section{Subjects}

Forty-eight healthy, medication-free volunteers were recruited through public advertisement to participate in the study. Subjects were between 18 and 61 y old (mean \pm SD, $30 \pm 10$ y). Thirtythree $(69 \%)$ were male. Thirty-seven $(77 \%)$ were Caucasian, 5 (10\%) were African-American, and 2 each were Hispanic, Asian-American, or multiracial. One subject (26 y old) was 
excluded on statistical grounds ( $>3$ SDs above the mean cortical nondisplaceable binding potential $\left.\left[\mathrm{BP}_{\mathrm{ND}}\right]\right)$.

All subjects had a comprehensive screening assessment that included a complete physical examination with medical history, routine blood tests, pregnancy test, urine toxicology, and electrocardiography and a psychiatric evaluation with application of the structured clinical interview for diagnosis of axis I disorders from the Diagnostic and Statistical Manual of Mental Disorders, fourth edition. Individuals were excluded if they reported a diagnosis of current or lifetime axis I or II psychiatric disorders; current or past serious medical or neurologic illness (including a history of head injury with loss of consciousness); current pregnancy (as documented by pregnancy testing at screening and on the day of the PET study) or breast feeding; general MRI exclusion criteria; and significant alcohol or illicit substance abuse or dependence in the past $3 \mathrm{mo}$. All subjects were medication-free for a minimum of 6 wk at the time of the scan.

The study was performed under protocols approved by the Yale Human Investigation Committee, the Human Subjects Subcommittee of the Veterans Affairs Connecticut Healthcare System, the Yale University Radiation Safety Committee, the Yale-New Haven Hospital Radiation Safety Committee, and the Yale MRI Safety Committee. Subjects were recruited from New Haven and surrounding areas by advertisement, word of mouth, and referrals. Written informed consent was obtained from all participants after a full explanation of study procedures.

\section{Radiochemistry}

${ }^{11} \mathrm{C}-\mathrm{P} 943$ ( $R$-1-[4-(2-methoxy-isopropyl)-phenyl]-3-[2-(4-methylpiperazin-1-yl)benzyl]-pyrrolidin-2-one) was prepared as previously described (15) by $\mathrm{N}$-methylation of the precursor with ${ }^{11} \mathrm{C}$-methyl triflate, using the PETtrace cyclotron and a TRACERLab FxC automated synthesizer (GE Healthcare). The GE Microlab was used in some of the preparations as a source of the requisite ${ }^{11} \mathrm{C}$-methyl iodide.

\section{Scanning and Imaging Procedures}

PET was performed with the selective $5-\mathrm{HT}_{1 \mathrm{~B}}$ antagonist radiotracer ${ }^{11} \mathrm{C}$-P943. All scanning was performed on a high-resolution research tomograph (Siemens/CTI), which acquired 207 slices (1.2-mm slice separation) with a reconstructed image resolution of about $3 \mathrm{~mm}$. A transmission scan with a ${ }^{137} \mathrm{Cs}$ point source was obtained before the emission scan. The PET scans were acquired for $120 \mathrm{~min}$ at rest with a single intravenous injection of $630 \pm$ $132 \mathrm{MBq}$ and a high specific activity of $161 \pm 71 \mathrm{MBq} / \mathrm{nmol}$.

Structural MR images were obtained on a 3-T Trio system (Siemens Medical Solutions) with a circularly polarized head coil for each subject to exclude individuals with anatomic abnormalities and for coregistration. The dimension and voxel size of MR images were $256 \times 256 \times 176$ and $0.98 \times 0.98 \times 1.0 \mathrm{~mm}$, respectively.

Dynamic PET scan data were reconstructed with all corrections (attenuation, normalization, scatter, randoms, dead time, and motion), using the MOLAR algorithm (16) with the following frame timing: $6 \times 30 \mathrm{~s}, 3 \times 1 \mathrm{~min}, 2 \times 2 \mathrm{~min}$, and $22 \times 5 \mathrm{~min}$. Motion was additionally corrected by image smoothing with a gaussian filter of $3 \mathrm{~mm}$ in full width at half maximum and either by using an optical detector (Vicra; NDI Systems) or by coregistering each frame image to an early summed image (0-10 min after injection) with a 6-parameter mutual information algorithm (FLIRT, FSL 3.2; Analysis Group, FMRIB). Both motion corrections were added as a covariate in further analysis, and no significant differences were found in any of the regions studied $\left(F_{1,45}=0.01, P=0.9144\right)$. As in pre- vious P943 studies, PET data were used to produce a time-activity curve for the cerebellum, which was used as a reference. The multilinear reference tissue model has been previously validated in a P943 study and was used to produce parametric images of $\mathrm{BP}_{\mathrm{ND}}$ (17).

A second summed image (0-10 min after injection) was created from the motion-corrected PET data and registered to the subject's MR image, which in turn was registered (12-parameter affine transformation) to an MRI template (Montreal Neurologic Institute space).

Regions of interest were based on the Anatomic Automatic Labeling template delineated on an MRI template (18). The primary region was the cerebral cortex, which was a summed result of the frontal, occipital, parietal, and temporal cortices. A secondary analysis examined subcortical areas (amygdala, caudate, hippocampus, hypothalamus, pallidum, putamen, and thalamus). These results were obtained using individual parametric images that were resliced in template space using the PET-to-MRI and the MRI-to-template transforms.

To account for possible partial-volume effects, a binary gray matter mask (GMM) was used. For these results, individual MR images were segmented with FAST (FMRIB's Automated Segmentation Tool, version 3.1) to obtain masking of gray matter, white matter, and cerebrospinal fluid. The individual GMMs were then applied to the regions from the Anatomic Automatic Labeling template to obtain the mean regional values limited to gray matter voxels.

\section{Statistical Analysis}

All outcomes were summarized descriptively and assessed for normality before analysis using normal probability plots and Kolmogorov test statistics. All outcomes were approximately normal. Correlations between age and $5-\mathrm{HT}_{1 \mathrm{~B}}$ were calculated separately within, and averaged across, each region. A linear mixed model was used to model the independent and joint effects of age (continuous) and cortical region (within-subject factor) on $\mathrm{BP}_{\mathrm{ND}}$ values. The interaction between region and age was modeled, and slopes for each cortical region were estimated post hoc. Within-subject correlations were accounted for by fitting 3 variance-covariance structures to the data (unstructured, compound symmetry, and heterogeneous compound symmetry) and then selecting the best-fitting structure according to the Bayesian information criterion. Subcortical regions were analyzed as secondary subregions and adjusted using the Bonferroni adjustment. All analyses were conducted using SAS, version 9.1 (SAS Institute Inc.).

\section{RESULTS}

Table 1 presents average $5-\mathrm{HT}_{1 \mathrm{~B}}( \pm \mathrm{SD}) \mathrm{BP}_{\mathrm{ND}}$ levels for cortical and segmented cortical gray matter regions, along with the slope and correlations with age in the 47 reported subjects. Significant negative associations between age and $5-\mathrm{HT}_{1 \mathrm{~B}} \mathrm{BP}_{\mathrm{ND}}$ were observed in all cortical regions, and total cortical $\mathrm{BP}_{\mathrm{ND}}$ averaged an $8 \%$ decline per decade studied (9\% in total cortical gray matter using GMM).

The results of the primary mixed model showed an overall significant effect of age on both total $\mathrm{BP}_{\mathrm{ND}}\left(F_{1,45}=\right.$ 21.6, $P<0.0001)$ and total $\mathrm{BP}_{\mathrm{ND}}$ after $\operatorname{GMM}\left(F_{1,45}=\right.$ 28.6, $P<0.0001$ ), averaged across all cortical regions. These effects are depicted in Figures 1 and 2, respectively. Consistent with the univariate results, primary mixedmodel slope estimates for the individual 5- $\mathrm{HT}_{1 \mathrm{~B}} \mathrm{BP}_{\mathrm{ND}}$ cor- 
TABLE 1

Regional Mean $\mathrm{BP}_{\mathrm{ND}}$, Correlations Between Age and ${ }^{11} \mathrm{C}-\mathrm{P} 943 \mathrm{BP}_{\mathrm{ND}}$, and Slope for Cortical Regions of Interest

\begin{tabular}{|c|c|c|c|c|c|c|}
\hline \multirow[b]{2}{*}{ Region ( $n=47$ participants) } & \multicolumn{2}{|c|}{$\mathrm{BP}_{\mathrm{ND}}$} & \multirow[b]{2}{*}{ Pearson $R$} & \multicolumn{2}{|c|}{ Slope } & \multirow[b]{2}{*}{$P$} \\
\hline & Mean & SD & & Value & SE & \\
\hline \multicolumn{7}{|l|}{ Cortical regions of interest } \\
\hline Frontal & 0.92 & 0.15 & -0.48 & -0.0067 & 0.002 & $<0.0001$ \\
\hline Occipital & 0.85 & 0.13 & -0.53 & -0.0067 & 0.002 & $<0.0001$ \\
\hline Parietal & 0.74 & 0.13 & -0.61 & -0.0076 & 0.002 & $<0.0001$ \\
\hline Temporal & 0.76 & 0.11 & -0.48 & -0.0053 & 0.002 & $<0.001$ \\
\hline Total cortex & 0.82 & 0.15 & -0.57 & -0.0066 & 0.001 & $<0.0001$ \\
\hline \multicolumn{7}{|c|}{ Cortical regions of interest (with GMM) } \\
\hline Frontal & 1.25 & 0.15 & -0.62 & -0.0087 & 0.002 & $<0.0001$ \\
\hline Occipital & 1.03 & 0.14 & -0.56 & -0.0075 & 0.002 & $<0.0001$ \\
\hline Parietal & 0.92 & 0.13 & -0.66 & -0.0084 & 0.001 & $<0.0001$ \\
\hline Temporal & 0.88 & 0.11 & -0.52 & -0.0052 & 0.001 & $<0.0001$ \\
\hline Total cortex & 0.99 & 0.16 & -0.62 & -0.0075 & 0.001 & $<0.0001$ \\
\hline
\end{tabular}

tical regions (with and without GMM) remained significant $(P=<0.01)$ with age (Figs. 3 and 4 , respectively).

Subcortical region (without GMM) correlations were largely insignificant when age and $5-\mathrm{HT}_{1 \mathrm{~B}} \mathrm{BP}_{\mathrm{ND}}$ were examined, with the exception of the hypothalamus $(r=-0.28$, $P=0.05)$, pallidum $(r=+0.39, P=0.01)$, and putamen ( $r=+0.41, P<0.01)$. GMM subcortical results found a difference in the putamen $(r=+0.32, P=0.03)$ and a trend-level difference in the pallidum $(r=+0.26, P=0.08)$, with all other regions nonsignificant. Subcortical results remained significant after a multiple-comparison correction in the pallidum (Bonferroni-adjusted $P=0.05$ ) and putamen (Bonferroni-adjusted $P=0.03$ ) without GMM.

Sex and race had no significant effects on these results.

\section{DISCUSSION}

This work has furthered our understanding of the role of aging on the serotonin system by demonstrating age effects on $5-\mathrm{HT}_{1 \mathrm{~B}}$ with the PET radiotracer ${ }^{11} \mathrm{C}$-P943. A decrease in $\mathrm{BP}_{\mathrm{ND}}$ was found throughout cortical areas with increased age. These findings are consistent with the existing literature on aging and serotonin, which has shown decreases in the density of $5-\mathrm{HT}_{1 \mathrm{~A}}$ and $5-\mathrm{HT}_{2 \mathrm{~A}}$ in aging $(3-6,8,19)$.

Different methods to control for cerebral atrophy were used in these cited studies. The current work used a gray

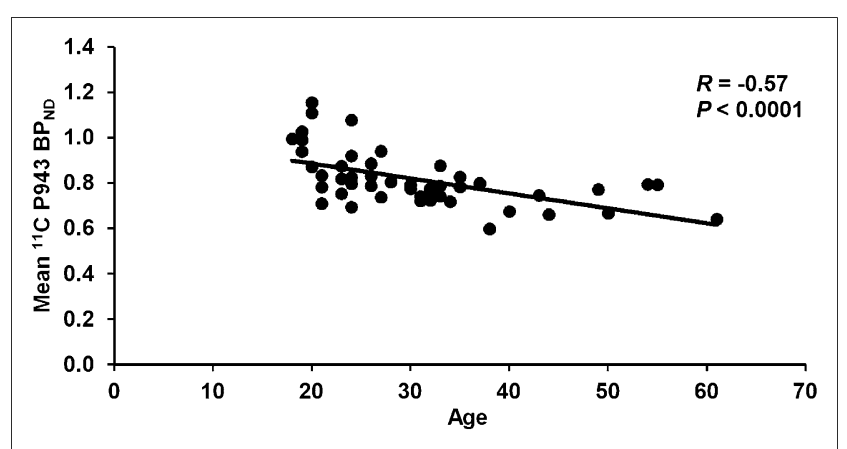

FIGURE 1. Mean cortical $\mathrm{BP}_{\mathrm{ND}}$ for each subject along with age (in years). matter segmentation to create a gray matter binary mask, and although this method is not necessarily sensitive to all partial-volume effects, the retention of findings argues against the possibility that cerebral atrophy is responsible for the decreases in $5-\mathrm{HT}_{1 \mathrm{~B}}$ with aging. Furthermore, a recent study that examined $5-\mathrm{HT}_{2 \mathrm{~A}}$ and aging found that a partial-volume correction was not necessary when similar parameters (cortical regions of interest, high-resolution scanning, and a healthy population) were examined (19).

Our sample comprised mostly male subjects (69\%) who were younger than $61 \mathrm{y}$, and the sample was also limited in distribution across age regions (with most subjects under $40 \mathrm{y}$ ). This is a limitation to the current analysis, as it is susceptible to bias induced by fewer older subjects and sex (although no current sex effects were found). Further studies including a more balanced distribution of older subjects could be justified to verify that $5-\mathrm{HT}_{1 \mathrm{~B}}$ decline is a linear phenomenon in advanced age. Although the multilinear reference tissue model is a validated method to examine these data, another potential limitation in this study was the lack of available arterial blood flow data in most subjects to rule out potential confounders such as age-related effects of the cerebellar time-activity curve.

The preliminary finding of increased $5-\mathrm{HT}_{1 \mathrm{~B}} \mathrm{BP}_{\mathrm{ND}}$ in the pallidum and putamen (which retained significance after

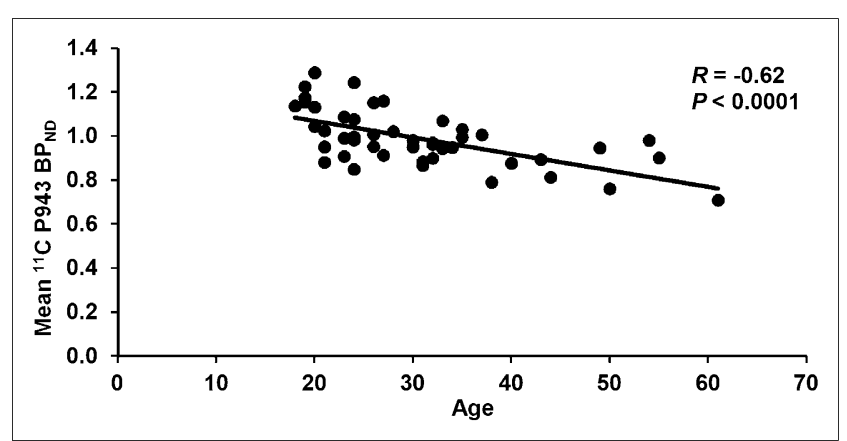

FIGURE 2. Mean cortical $\mathrm{BP}_{\mathrm{ND}}$ (after $\mathrm{GMM}$ ) for each subject along with age (in years). 


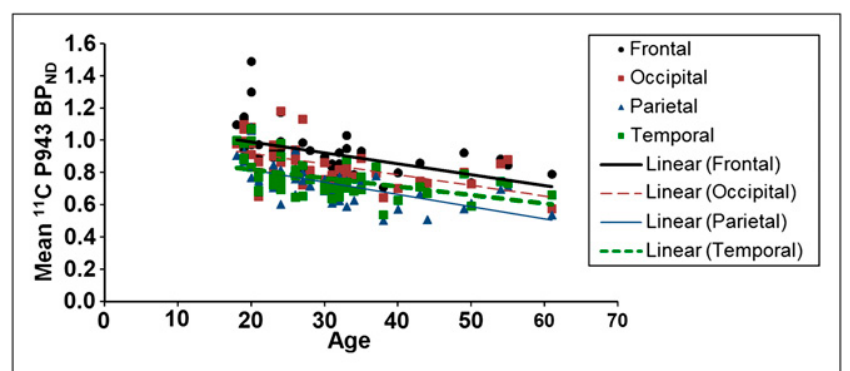

FIGURE 3. Mean $\mathrm{BP}_{\mathrm{ND}}$ for each cortical region along with age (in years).

multiple corrections) could be of interest, as there are no current reports of increasing serotonin receptor brain levels with age in any region. If confirmed in further work, these subcortical areas could be a focus of a potentially novel process.

Finally, whereas the focus of this paper was to investigate age effects on $5-\mathrm{HT}_{1 \mathrm{~B}}$, the functional impact of this finding could extend into cognitive effects such as memory or learning that have been implicated in $5-\mathrm{HT}_{1 \mathrm{~B}}$ decline in a host of preclinical work $(1,9,14)$. In the only other work to date on an aged human population, postmortem examination found reduced 5- $\mathrm{HT}_{1 \mathrm{~B}}$ density in Alzheimer patients, compared with controls, in the frontal and temporal cortices (20). Interestingly, cognitive decline was associated with more $5-\mathrm{HT}_{1 \mathrm{~B}}$ in that study. The authors attributed this finding to a compensation of 5- $\mathrm{HT}_{1 \mathrm{~B}}$ heteroreceptors for a deteriorated cholinergic system (i.e., the heteroreceptors, which function to inhibit acetylcholine, led to worse cognitive performance due to decreased acetylcholine in an already acetylcholine-deficient state in Alzheimer disease). It remains to be seen if 5- $\mathrm{HT}_{1 \mathrm{~B}}$ medications could have a clinical effect on age-specific cognitive problems, but the current results support further investigation of this potential learning and memory treatment.

\section{CONCLUSION}

The findings of this study indicate that age is a relevant factor for $5-\mathrm{HT}_{1 \mathrm{~B}}$ in the cortex of healthy adults.

\section{DISCLOSURE STATEMENT}

The costs of publication of this article were defrayed in part by the payment of page charges. Therefore, and solely

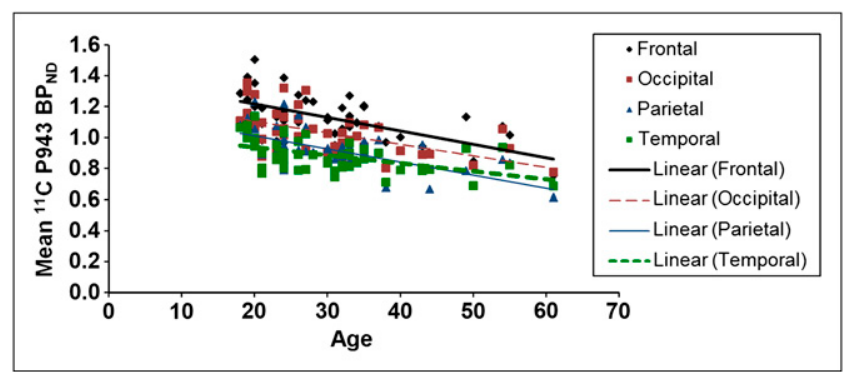

FIGURE 4. Mean $\mathrm{BP}_{\mathrm{ND}}$ (after $\mathrm{GMM}$ ) for each cortical region along with age (in years). to indicate this fact, this article is hereby marked "advertisement" in accordance with 18 USC section 1734.

\section{ACKNOWLEDGMENTS}

Both the P943 standard and the $N$-desmethyl precursor were provided by Pfizer, Inc. (Groton, CT). This project was supported by the National Institutes of Health through the following awards: R21 MH081103 (ARRA), R21 MH085627, and R21 AA018329. This project was also supported in part by the Research Council of Norway, Division for Science. Zubin Bhagwagar is a full-time employee of Bristol-Meyers Squibb. No other potential conflict of interest relevant to this article was reported.

\section{REFERENCES}

1. Sibille E, Su J, Leman S, et al. Lack of serotonin1B receptor expression leads to age-related motor dysfunction, early onset of brain molecular aging and reduced longevity. Mol Psychiatry. 2007;12:1042-1056.

2. Meltzer CC, Reynolds CF III. In vivo assessment of aging changes in serotonin function. Neuropsychopharmacology. 1999;21:323-324.

3. Meltzer CC, Smith G, Price JC, et al. Reduced binding of $\left[{ }^{18} \mathrm{~F}\right]$ altanserin to serotonin type $2 \mathrm{~A}$ receptors in aging: persistence of effect after partial volume correction. Brain Res. 1998;813:167-171.

4. Versijpt J, Van Laere KJ, Dumontc F, et al. Imaging of the 5-HT2A system: age-, gender-, and Alzheimer's disease-related findings. Neurobiol Aging. 2003;24:553-561.

5. Tauscher J, Verhoeff NP, Christensen BK, et al. Serotonin 5-HT1A receptor binding potential declines with age as measured by $\left[{ }^{11} \mathrm{C}\right] \mathrm{WAY}-100635$ and PET. Neuropsychopharmacology. 2001;24:522-530.

6. Baeken C, D'haenen H, Flamen P, et al. ${ }^{123}$ I-5-I-R91150, a new single-photon emission tomography ligand for 5-HT2A receptors: influence of age and gender in healthy subjects. Eur J Nucl Med. 1998;25:1617-1622.

7. Goldberg S, Smith GS, Barnes A, et al. Serotonin modulation of cerebral glucose metabolism in normal aging. Neurobiol Aging. 2004;25:167-174.

8. Costes N, Merlet I, Ostrowsky K, et al. A ${ }^{18} \mathrm{~F}$ MPPF PET normative database of 5-HT1A receptor binding in men and women over aging. J Nucl Med. 2005;46:1980-1989.

9. David DJ, Bourin M, Hascoet M, et al. Comparison of antidepressant activity in 4- and 40-week-old male mice in the forced swimming test: involvement of 5-HT1A and 5- HT1B receptors in old mice. Psychopharmacology (Berl). 2001;153:443-449.

10. Sari Y. Serotonin1B receptors: from protein to physiological function and behavior. Neurosci Biobehav Rev. 2004;28:565-582.

11. Hu J, Henry S, Gallezot J-D, et al. Serotonin 1B receptor imaging in alcohol dependence. Biol Psychiatry. 2010;67:800-803.

12. Murrough JW, Henry S, Hu J, et al. Reduced ventral striatal/ventral pallidal serotonin1B receptor binding potential in major depressive disorder. Psychopharmacology (Berl). 2011;213:547-553.

13. Murrough JW, Czermak C, Henry S, et al. The effect of early trauma exposure on serotonin type $1 \mathrm{~B}$ receptor expression revealed by reduced selective radioligand binding. Arch Gen Psychiatry. 2011;68:892-900.

14. Mitchell ES, McDevitt RA, Neumaier JF. Adaptations in 5-HT receptor expression and function: implications for treatment of cognitive impairment in aging. J Neurosci Res. 2009;87:2803-2811.

15. Nabulsi N, Huang Y, Weinzimmer D, et al. High resolution imaging of brain 5-HT $\mathrm{H}_{1 \mathrm{~B}}$ receptors in the rhesus monkey using $\left[{ }^{11} \mathrm{C}\right] \mathrm{P} 943$. Nucl Med Biol. 2010;37:205-214.

16. Johnson CA, Thada S. Rodriguez, et al. Software architecture of the MOLARHRRT reconstruction engine. IEEE Nucl Sci Symp Conf Rec. 2004;6:3956-3960.

17. Gallezot JD, Nabulsi N, Neumeister A, et al. Kinetic modeling of the serotonin 5-HT(1B) receptor radioligand $\left[{ }^{11} \mathrm{C}\right] \mathrm{P} 943$ in humans. J Cereb Blood Flow Metab. 2010;30:196-210.

18. Tzourio-Mazoyer N, Landeau B, Papathanassiou D, et al. Automated anatomical labeling of activations in SPM using a macroscopic anatomical parcellation of the MNI MRI single subject brain. Neuroimage. 2002;15:273-289.

19. Uchida H, Chow TW, Mamo DC, et al. Effects of aging on 5-HT2AR binding: a HRRT PET study with and without partial volume corrections. Int J Geriatr Psychiatry. 2011;26:1300-1308.

20. Garcia-Alloza M, Hirst WD, Chen CPLH, et al. Differential involvement of $5-\mathrm{HT}_{1 \mathrm{~B}} / 1 \mathrm{D}$ and $5-\mathrm{HT}_{6}$ receptors in cognitive and non-cognitive symptoms in Alzheimer's disease. Neuropsychopharmacology. 2004;29:410-416. 